7 Tiberi S, Payen MC, Sotgiu G, et al. Effectiveness and safety of meropenem/clavulanate-containing regimens in the treatment of multidrug and extensively drug-resistant tuberculosis. Eur Respir J 2016; 47: 1235-1243.

8 Tiberi S, Sotgiu G, D’Ambrosio L, et al. Comparison of effectiveness and safety of imipenem/clavulanate-versus meropenem/clavulanate-containing regimens in the treatment of multidrug and extensively drug-resistant tuberculosis. Eur Respir J 2016; 47: 1758-1766.

9 Tiberi S, Sotgiu G, D'Ambrosio L, et al. Effectiveness and safety of imipenem-clavulanate added to an optimized background regimen (OBR) versus OBR control regimens in the treatment of multidrug-resistant and extensively drug-resistant tuberculosis. Clin Infect Dis 2016; 62: 1188-1190.

10 Piubello A, Harouna SH, Souleymane MB, et al. High cure rate with standardised short-course multidrug-resistant tuberculosis treatment in Niger: no relapses. Int J Tuberc Lung Dis 2014; 18: 1188-1194.

11 Van Deun A, Maug AK, Salim MA, et al. Short, highly effective, and inexpensive standardized treatment of multidrug-resistant tuberculosis. Am J Respir Crit Care Med 2010; 182: 684-692.

12 Aung KJ, Van Deun A, Declercq E, et al. Successful '9-month Bangladesh regimen' for multidrug-resistant tuberculosis among over 500 consecutive patients. Int J Tuberc Lung Dis 2014; 18: 1180-1187.

13 Ghimire S, Bolhuis MS, Sturkenboom MG, et al. Incorporating therapeutic drug monitoring into the World Health Organization hierarchy of tuberculosis diagnostics. Eur Respir J 2016; 47: 1867-1869.

14 Tiberi S, D'Ambrosio L, De Lorenzo S, et al. Tuberculosis elimination, patients' lives and rational use of new drugs: revisited. Eur Respir J 2016; 47: 664-667.

15 D'Ambrosio L, Tadolini M, Dupasquier S, et al. ERS/WHO tuberculosis consilium: reporting of the initial 10 cases. Eur Respir J 2014; 43: 286-289.

\title{
Variation in vitamin D deficiency among tuberculosis patients by ethnic group and geographical region of birth: evidence from a diverse south London population
}

\author{
To the Editor:
}

Numerous studies have demonstrated an important association of vitamin D deficiency with tuberculosis (TB) $[1,2]$. Vitamin $\mathrm{D}$ is important for immune function and an appropriate host response to Mycobacterium tuberculosis [3, 4]; 25-hydroxyvitamin D $(25(\mathrm{OH}) \mathrm{D})$ is the primary circulating form of vitamin $\mathrm{D}$ and is used to measure deficiency.

We have previously demonstrated that, although vitamin D deficiency is common in south-east London, patients with TB have significantly lower serum $25(\mathrm{OH}) \mathrm{D}$ than healthy controls matched for age, sex, ethnicity, diet and geographical location [1], with particularly low levels found in TB patients of certain Asian and African ethnicities [2]. Trials of vitamin D supplementation during TB therapy have produced mixed results, particularly with certain vitamin D receptor (VDR) polymorphisms $[5,6]$.

In this study, we aimed to investigate the effect of both ethnicity and region of birth on the $25(\mathrm{OH}) \mathrm{D}$ levels of TB patients living in the UK.

Patients diagnosed with TB between January 2001 and September 2012 at two large south London hospitals were identified retrospectively from the London TB Register and in-house databases. Demographic data, country of birth, year of entry into the UK, TB site (pulmonary or extrapulmonary), treatment dates, 25(OH)D levels and HIV status were extracted.

Patients were included if they had a 25(OH)D level recorded within 6 months before, or 1 month after, starting treatment. Patients with chronic kidney disease on dialysis were excluded.

Country of birth was categorised as Africa (excluding the Horn of Africa); Horn of Africa (Eritrea, Ethiopia, Kenya, Somalia, Sudan); Americas (North and South); Asia (excluding the Indian subcontinent); Indian subcontinent (Bangladesh, India, Pakistan, Sri Lanka); Caribbean; and Europe (including the UK).

Ethnicity was reported by the patient and categories used for analysis were: white, including Irish, European and Latin American; black, including black African, black Other and black Caribbean; Indian Asian for Bangladeshi, Indian and Pakistani; Asian, including Asian, Chinese and Vietnamese; and Other. Patients with missing ethnicity data were recorded as missing. 
The quarter in which the $25(\mathrm{OH}) \mathrm{D}$ level was tested was recorded as winter (December-February), spring (March-May), summer (June-August) or autumn (September-November); 25(OH)D status was defined as deficient $\left(<20 \mathrm{nmol} \cdot \mathrm{L}^{-1}\right)$, insufficient $\left(20-60 \mathrm{nmol} \cdot \mathrm{L}^{-1}\right)$ and normal $\left(>60 \mathrm{nmol} \cdot \mathrm{L}^{-1}\right)$.

The primary outcome variable was vitamin D deficiency $\left(25(\mathrm{OH}) \mathrm{D}<20 \mathrm{nmol} \cdot \mathrm{L}^{-1}\right)$ and better than deficient $\left(25(\mathrm{OH}) \mathrm{D} \geqslant 20 \mathrm{nmol} \cdot \mathrm{L}^{-1}\right)$. A secondary outcome variable was normal $\left(25(\mathrm{OH}) \mathrm{D}>60 \mathrm{nmol} \cdot \mathrm{L}^{-1}\right)$ and less than normal if not. The exposure variables were ethnicity and region of birth. Age, sex, TB site, being born in the UK and the number of years spent in the UK were all considered potential confounders for the association between vitamin D deficiency and ethnicity/region of birth.

Levels of 25(OH)D were compared using Chi-squared tests. Logistic regression models produced crude and adjusted odds ratios for $25(\mathrm{OH}) \mathrm{D}$ deficiency by ethnic group and region of birth, adjusted odds ratio having been adjusted for age, sex, TB site and HIV status. Likelihood ratio tests were used to establish the confounding factors to be included in the logistic regression models. The level of significance was defined as $\mathrm{p}<0.05$.

Of 2602 patients diagnosed with TB, 728 fulfilled the inclusion criteria. For the variables of sex, region of birth, TB site and ethnicity, data were missing for $<3 \%$ of patients. Length of stay in the UK was unknown for $28 \%$ of patients born abroad. HIV status was unknown for $27 \%$ of patients.

In total, $40 \%$ of patients were $25(\mathrm{OH}) \mathrm{D}$-deficient $\left(<20 \mathrm{nmol} \cdot \mathrm{L}^{-1}\right), 50 \%$ had insufficient levels $\left(20-60 \mathrm{nmol} \cdot \mathrm{L}^{-1}\right)$ and $9 \%$ normal levels $\left(>60 \mathrm{nmol} \cdot \mathrm{L}^{-1}\right)$. Mean $\left.25(\mathrm{OH}) \mathrm{D}\right)$ was $29.6 \mathrm{nmol} \cdot \mathrm{L}^{-1}\left(\right.$ median $=22 \mathrm{nmol} \cdot \mathrm{L}^{-1}$ ). In adults, $25(\mathrm{OH}) \mathrm{D}$ deficiency was less common across increasing age groups $(\mathrm{p}=0.0012)$.

Diagnosis of TB was evenly distributed among the four quarters of the year with no seasonal peak, although $30 \%$ of patients tested for $25(\mathrm{OH}) \mathrm{D}$ in summer were deficient compared with $52 \%$ tested in winter.

Having adjusted for age, sex, TB site and HIV status, Indian (Asian) patients were 10 times more likely to be deficient (adjusted OR 10.10, 95\% CI 4.52-22.57) and black patients were three times more likely to be deficient than white patients (adjusted OR 3.28, 95\% CI 1.76-6.10). After adjustments, only patients born in the Horn of Africa (adjusted OR 6.07, 95\% CI 3.26-11.30) and the Indian subcontinent (adjusted OR 7.07, 95\% CI 3.26-15.33) were significantly more likely to be $25(\mathrm{OH}) \mathrm{D}$-deficient than patients born in Europe (table 1).

Furthermore, patients born in the Horn of Africa were seven times more likely to be deficient than those born in the rest of Africa (adjusted OR 7.31, 95\% CI 3.96-13.49). Patients born in the Indian subcontinent were 11 times more likely to be 25(OH)D-deficient than patients born in the rest of Asia (adjusted OR 11.85, 95\% CI 3.97-35.39). Having adjusted for ethnicity, being born in Europe (including the UK) conferred neither any significant protection nor risk of being 25(OH)D-deficient (adjusted OR 0.84, 95\% CI 0.47-1.50).

Extrapulmonary TB was more common in patients meeting the inclusion criteria than the total study population, with ethnicity being a factor affecting TB site and both being known to be associated with variation in vitamin D levels [7].

Genetic susceptibility to vitamin D deficiency may play an important role in the increased risk of deficiency in certain ethnicities. Previous studies have found ethnic variations in TB disease phenotypes [7, 8] with evidence that this may be due to genetic differences in the VDR. Ethnicity is a powerful determinant of clinical TB phenotype [8]. Recent evidence has also demonstrated variations in the vitamin D-binding protein between ethnicities in TB patients [9], relating to ethnic differences in the inflammatory profile. Martineau et al. [10] found that the association between the Gc2/2 genotype and susceptibility to TB is dependent on vitamin D status.

The evidence for vitamin $\mathrm{D}$ levels and skin type is conflicting $[11,12]$. While it is possible that the differences between white and black or Asian patients are due to skin pigmentation, this cannot account for the differences demonstrated between patients from the Horn of Africa and the rest of Africa, or indeed the Indian subcontinent and the rest of Asia.

Diet has previously been shown to have no effect on vitamin D status in TB patients compared with household contacts [1]. Although dietary differences could be partially responsible for the demonstrated differences between black, Asian and white patients, it is unlikely that the same can be said for the differences seen in patients from the Horn of Africa and the Indian subcontinent compared with other African and Asian patients.

Our figures suggest that HIV coinfection may be protective against vitamin D deficiency. This was an unexpected finding and was not explored further as numbers were small and more detailed data were not available on these patients, but suggests an avenue for future research.

The retrospective nature of the study meant that there were many potentially significant factors, such as supplementation, relevant to $25(\mathrm{OH}) \mathrm{D}$ deficiency in these $\mathrm{TB}$ patients for which no information was available. Although $25(\mathrm{OH}) \mathrm{D}$ levels were not measured in all $\mathrm{TB}$ patients, this reflected awareness of deficiency of the managing doctor. However, this study included a larger cohort with greater ethnic diversity 
TABLE 1 Patient demographics, ethnicity and region of birth: odds ratios for vitamin D deficiency

\begin{tabular}{|c|c|c|c|c|}
\hline & & \multicolumn{3}{|c|}{ ORs for $25(\mathrm{OH}) \mathrm{D}$ deficiency } \\
\hline & & Crude $\mathrm{OR}^{\#}(95 \% \mathrm{Cl})$ & Adjusted OR $(95 \% \mathrm{CI})$ & $\mathrm{p}$-value \\
\hline \multicolumn{5}{|l|}{ Age years } \\
\hline $17-29$ & $211(29.0)$ & $1.44(0.98-2.10)$ & $1.18(0.74-1.88)^{+}$ & 0.482 \\
\hline $30-39$ & $218(30.0)$ & 1.0 (baseline) & 1.0 (baseline) & \\
\hline $40-49$ & $111(15.3)$ & $0.92(0.57-1.46)$ & $1.05(0.57-1.91)^{+}$ & 0.88 \\
\hline \multicolumn{5}{|l|}{ Sex } \\
\hline Male & 406 (56.3) & 1.0 (baseline) & 1.0 (baseline) & \\
\hline Female & $315(43.7)$ & $0.85(0.54-1.34)$ & $0.71(0.48-1.05)^{+}$ & 0.087 \\
\hline \multicolumn{5}{|l|}{ TB site } \\
\hline Pulmonary & $345(47.3)$ & 1.0 (baseline) & 1.0 (baseline) & \\
\hline Extrapulmonary & $383(52.5)$ & $1.77(1.31-2.40)$ & $1.17(0.78-1.76)^{+}$ & 0.45 \\
\hline \multicolumn{5}{|l|}{ HIV status } \\
\hline White & $127(17.9)$ & 1.0 (baseline) & 1.0 (baseline) & \\
\hline Indian (Asian) & 105 (14.8) & $9.74(5.31-17.85)$ & $10.10(4.52-22.56)^{+}$ & $<0.001$ \\
\hline Black & $393(55.5)$ & $3.08(1.90-4.98)$ & $3.28(1.76-6.10)^{+}$ & $<0.001$ \\
\hline Asian (Other) & $45(6.4)$ & $1.32(0.59-2.96)$ & $1.07(0.38-2.99)^{+}$ & 0.905 \\
\hline Other & $38(5.4)$ & $1.88(0.84-4.24)$ & $2.28(0.86-6.04)^{+}$ & 0.098 \\
\hline \multicolumn{5}{|l|}{ Region of birth } \\
\hline Africa & $170(23.7)$ & $1.06(0.67-1.67)$ & $0.81(0.46-1.43)^{\S}$ & 0.46 \\
\hline Horn of Africa & $132(18.4)$ & $6.43(3.96-10.43)$ & $6.07(3.26-11.30)^{\S}$ & $<0.001$ \\
\hline Americas & $26(3.6)$ & $0.11(0.14-0.81)$ & $0.095(0.01-0.74)^{\S}$ & 0.025 \\
\hline Asia & $61(8.5)$ & $0.96(0.50-1.83)$ & $0.82(0.64-5.40)^{\S}$ & 0.638 \\
\hline Indian subcontinent & 95 (18.4) & $7.16(4.14-12.35)$ & $7.07(3.26-15.34)^{\S}$ & $<0.001$ \\
\hline Caribbean & $25(3.5)$ & $1.80(0.76-4.23)$ & $1.86(0.64-5.40)^{\S}$ & 0.252 \\
\hline
\end{tabular}

Data are presented as $\mathrm{n}(\%)$, unless otherwise stated. 25(OH)D: 25-hydroxyvitamin D; TB: tuberculosis. ${ }^{\text {: }}$ crude odds ratio is the crude odds ratio for $25(\mathrm{OH}) \mathrm{D}$ deficiency in a given exposure category compared to the baseline group, as indicated; ${ }^{\text {?: }}$ adjusted odds ratio is the adjusted odds ratio for $25(\mathrm{OH}) \mathrm{D}$ deficiency in a given exposure category compared to the baseline group, as indicated; ${ }^{+}$: adjusted for age, sex, TB site, HIV status and ethnicity; ${ }^{\S}$ : adjusted for age, sex, TB site and HIV status; ${ }^{f}$ : odds ratios not available.

than many others. Finally, it was not possible to control for diet, supplementation or socioeconomic status, but results were calculated after adjusting for known important confounders, such as age, sex and HIV status.

There is both a negative impact of low levels of vitamin D in TB $[13,14]$ and a therapeutic role for supplementation in TB treatment $[4,6]$. Our findings strongly suggest an association between certain ethnicities and vitamin D deficiency, and an association between particular geographical regions and an increased risk of deficiency. Further studies are required to identify the underlying mechanisms relating to the very high levels of deficiency in TB patients from the Horn of Africa and the Indian subcontinent, as has been reported here. This will have implications for understanding the role of vitamin D in TB aetiology and for the prevention and treatment of active tubercular disease in these patients. Vitamin D supplementation should be considered for such groups with latent TB infection as part of the strategy for working towards the elimination of TB in low TB incidence countries [15]. 
Adam Pilarski ${ }^{1}$, Nicole Penn ${ }^{1}$, Sharenja Ratnakumar ${ }^{1}$, Richard D. Barker ${ }^{2}$ and Heather J. Milburn ${ }^{1,3}$

${ }^{1}$ King's College London School of Medicine, London, UK. ${ }^{2}$ Dept of Respiratory Medicine, King's College Hospital, London,

UK. ${ }^{3}$ Dept of Respiratory Medicine, Guy's and St Thomas' NHS Foundation Trust, London, UK.

Correspondence: Heather J. Milburn, Chest Clinic, Guy’s Hospital, Great Maze Pond, London, SE1 9RT, UK.

E-mail: heather.milburn@gstt.nhs.uk

Received: Jan 022015 | Accepted after revision: July 162016 | First published online: Oct 062016

Conflict of interest: None declared.

Acknowledgements: The authors would like to thank Frank Post (GU Medicine, King's College Hospital, London, UK), Jessie Randhawa (Respiratory Medicine, Guy's and St Thomas' NHS Foundation Trust, London UK) and Vanessa Kahr (Respiratory Medicine, King's College Hospital, London, UK) for their support in the early stages of the project.

This report was a retrospective analysis of routine data, in which no personal identifiers were retained, and collected as part of clinical service provision.

H.J. Milburn and R.D. Barker conceived the study. N. Penn, A. Pilarski, S. Ratnakumar and R.D. Barker collected the data. N. Penn carried out the statistical analysis. With guidance from H.J. Milburn, N. Penn and A. Pilarski wrote the initial manuscript. A. Pilarski revised the manuscript with guidance from H.J. Milburn. All authors contributed to the completed manuscript.

\section{References}

1 Sita-Lumsden A, Lapthorn G, Swaminathan R, et al. Reactivation of tuberculosis and vitamin D deficiency: the contribution of diet and exposure to sunlight. Thorax 2007; 62: 1003-1007.

2 Ustianowski A, Shaffer R, Collin S, et al. Prevalence and associations of vitamin D deficiency in foreign-born persons with tuberculosis in London. J Infect 2005; 50: 432-437.

3 Prietl B, Treiber G, Pieber TR, et al. Vitamin D and immune function. Nutrients 2013; 5: 2502-2521.

4 Coussens AK, Wilkinson RJ, Hanifa Y, et al. Vitamin D accelerates resolution of inflammatory responses during tuberculosis treatment. Proc Natl Acad Sci USA 2012; 109: 15449-15454.

5 Martineau AR, Timms PM, Bothamley GH, et al. High-dose vitamin $\mathrm{D}(3)$ during intensive-phase antimicrobial treatment of pulmonary tuberculosis: a double-blind randomised controlled trial. Lancet 2011; 377: 242-250.

6 Salahuddin N, Ali F, Hasan Z, et al. Vitamin D accelerates clinical recovery from tuberculosis: results of the SUCCINCT Study [Supplementary Cholecalciferol in recovery from tuberculosis]. A randomized, placebocontrolled, clinical trial of vitamin D supplementation in patients with pulmonary tuberculosis. BMC Infect Dis 2013; 13: 22.

7 Pareek M, Innes J, Sridhar S, et al. Vitamin D deficiency and TB disease phenotype. Thorax 2015; 70: 1171-1180.

8 Pareek M, Evans J, Innes J, et al. Ethnicity and mycobacterial lineage as determinants of tuberculosis disease phenotype. Thorax 2013; 68: 221-229.

9 Coussens AK, Wilkinson RJ, Nikolayevskyy V, et al. Ethnic variation in inflammatory profile in tuberculosis. PLoS Pathog 2013; 9: e1003468.

10 Martineau AR, Leandro AC, Anderson ST, et al. Association between Gc genotype and susceptibility to TB is dependent on vitamin D status. Eur Respir J 2010; 35: 1106-1112.

11 Libon F, Cavalier E, Nikkels AF. Skin colour is relevant to vitamin D synthesis. Dermatology 2013; 227: 250-254.

12 Bogh MK, Schmedes AV, Philipsen PA, et al. Vitamin D production after UVB exposure depends on baseline vitamin D and total cholesterol but not on skin pigmentation. J Invest Dermatol 2010; 130: 546-553.

13 Gibney KB, MacGregor L, Leder K, et al. Vitamin D deficiency is associated with tuberculosis and latent tuberculosis infection in immigrants from sub-Saharan Africa. Clin Infect Dis 2008; 46: 443-446.

14 Talat N, Perry S, Parsonnet J, et al. Vitamin D deficiency and tuberculosis progression. Emerg Infect Dis 2010; 16: 853-855.

15 Lönnroth K, Migliori GB, Abubakar I, et al. Towards tuberculosis elimination: an action framework for low-incidence countries. Eur Respir J 2015; 45: 928-952.

\section{Association of pulmonary alveolar proteinosis and fibrosis: patient with GATA2 deficiency}

To the Editor:

Pulmonary alveolar proteinosis (PAP) is a rare syndrome characterised by an abnormal accumulation of surfactant proteins in pulmonary alveoli which impairs gas exchange [1]. PAP is classified into three groups: 